\title{
PERAWATAN DAN KEAMANAN ARSIP RAHASIA GEREJA: STUDI KASUS DI PAROKI ST. ANTONIUS KOTABARU, PAROKI KRISTUS RAJA BACIRO DAN PAROKI ST. YOHANES RASUL PRINGWULUNG
}

\author{
Ignatius Trisna Setiadi*), Y. Rudi Kriswanto**), \\ Universitas Gadjah Mada, Yogyakarta, Indonesia*) \\ Universitas Katolik Musi Charitas, Palembang, Indonesia**) \\ email: ignatius.trisna.s@mail.ugm.co.id*),rudi@ukmc.ac.id ${ }^{* *}$ )
}

Naskah diterima: 29 Oktober 2019; direvisi: 17 Januari 2020; disetujui: 28 Januari 2020

\begin{abstract}
Abstrak
Tulisan ini akan memberikan gambaran tentang bagaimana keamanan dan perawatan arsip rahasia Gereja. Studi kasus dilaksanakan di tiga paroki yakni paroki St. Antonius, Kotabaru, paroki St. Yohanes Rasul, Pringwulung, dan paroki Kristus Raja, Baciro. Alasan pemilihan ketiga paroki ini karena ketiganya saling keterkaitan dalam sejarah. Metode yang digunakan adalah pendekatan kualitatif. Pengumpulan data yang digunakan adalah wawancara mendalam dengan staff dan Pastor. Data dianalisis dengan membandingkan bagaimana perawatan dan keamanan arsip rahasia yang dilakukan di ketiga tempat tersebut. Hasil studi kasus dibahas dalam empat bagian yakni tentang ruang penyimpanan arsip rahasia, penyimpanan dan hak akses, pemeliharaan arsip rahasia dan usaha pencegahan kerusakan arsip rahasia gereja. Perawatan terhadap arsip rahasia, baru pada tahap bagaimana penyusunan yang rapi dan baik, penomoran (katalog). Upaya perawatan lainnya adalah pencegahan kerusakan dengan memasukkan arsip tersebut di dalam plastik. Standarisasi ruangan penyimpanan yang mampu menjaga arsip terhindar dari bencana alam maupun bencana lainnya, belum diupayakan.
\end{abstract}

Kata kunci: Arsip rahasia, Perawatan, Keamanan, Paroki

\begin{abstract}
This paper will provide an overview of how the security and persevation of the Church's secreat archive. This case study was conducted in three parishes; St. Antonius, Kotabaru, St. John the Apostle, Pringwulung, and Christ the King, Baciro parish. The reason for the election of these three parishes is because they are interconnected in history. This research is descriptive research using qualitative approach method. Data collection techniques used were in depth interviews with staff and Priest. The collected data were analyzed by comparing how the security and perservation of the secret archives were conducted in all three places. The case study results are discussed in four sections: the secret archive storage space, storage and access rights, the maintenance of the secret archive and the prevention of the destruction of the secret archives of the Church. Treatment of secret archives, new to the stage of how to make good and neat arrangements, numbering (catalog). Another treatment effort is the prevention of damage by inserting the file in plastic. Standarization of mamp storage space.
\end{abstract}

Keyword: Secret archives; Perservation; Security; Parish 


\section{PENDAHULUAN}

Arsip yang diproduksi atau ditulis seharihari merupakan sebuah pekerjaan yang penting dalam memenuhi kebutuhan administratif serta mendukung sebuah proses pengambilan keputusan pada sebuah institusi, organisasi, ataupun pemerintah. Arsip menyediakan sebuah bukti seperti; informasi, kemampuan simbolis, memori, akuntabilitas, legitimasi kekuasaan, identitas pribadi, dan identitas sosial secara berkelanjutan (Yeo, 2007 dalam Akuffo \& Adams, 2016). Oleh karena itu sebuah organisasi perlu memperhatikan pengelolaan arsip secara efisien dan efektif pada seluruh apek kehidupan organisasi tersebut.

Kearsipan menyadarkan kita akan kesatuan kita dengan masa lampau dan masa depan, memperluas wawasan kita dan sekaligus menyadarkan kita betapa pesatnya waktu berlalu, pemeran sejarah silih berganti, orang datang dan pergi (Go, 2006). Ada dua jenis arsip yakni 1) arsip dinamis yang terdiri dari arsip dinamis aktif dan inaktif, dan 2) arsip statis (Go, 2006: 19). Menurut UU RI No. 7/ Tahun 1971, arsip dinamis yakni yang dipergunakan secara langsung dalam perencanaan, penyelenggaraan kehidupan, sebaliknya arsip inaktif yakni arsip yang penggunaanya semakin berkurang. Arsip statis, yakni arsip yang tidak dipergunakan secara langsung dan melalui proses penilaian (aprasial) disimpan.

Ciri khas Gereja, mempunyai perutusan transenden, tetapi di lain pihak juga mengikuti sifat-sifat lembaga di dunia ini, menurut spesifikasi lebih lanjut untuk pengertian arsip (Go, 2006: 22). Tujuan diadakannya arsip gereja adalah adanya bahan untuk informasi yang benar tentang sejarah, agar ada bahan untuk rekonstruksi dan pembuktikan berdasarkan data yang benar. Selain itu, tujuan lainnya ialah adanya bahan pertimbangan untuk pengambilan keputusan yang tepat serta penetapan kebijakan yang mengena. Sebagai contohnya adalah jika seorang Katolik akan menikah, maka ia harus melengkapi data-data atau syarat perkawinan (yang ditemukan di arsip gereja). Salah satu syarat perkawinan adanya bukti telah dibaptis secara Katolik.
Pada bukti baptis inilah, seorang Imam akan mengetahui apakah ia dapat menikah atau tidak; terhalang perkawianannya atau tidak. Salah satu contohnya dalam Kanon 1088 tentang tidak sahlah perkawinan yang dicoba dilansungkan oleh mereka yang terikat kaul kekal publik kemurniaan dalam suatu tarekat religius (Rubiyatmoko, 2006). Jika terdapat keterangan bahwa orang tersebut telah mengucapkan kaul kekal publik maka mereka tidak bisa menikah.

Data-data yang penting dari seseorang khususnya tentang agama, disimpan dan dikelola pada setiap Gereja paroki dimana mereka berdomisili asal dan sekarang. Sebagai contoh seorang umat katolik berasal dari Lampung, maka data-data/ arsip umat tersebut berada di Lampung. Kemudian setelah lebih dari 3 bulan umat tersebut menetap di Yogyakarta, maka data tentang diri umat tersebut selanjutnya diarsipkan pada paroki terdekat/ yang berada dalam wilayah tempat tinggalnya di Yogyakarta. Data penting yang merupakan arsip perlu untuk dirawat dan dijaga agar tetap lestari, dan tetap bisa dimanfaatkan sampai kapan pun, bahkan ketika sudah meninggal. Perawatan terhadap sebagian besar arsip yang berupa kertas ini menjadi tantangan tersendiri dalam setiap paroki. Bagaimana arsip gereja ini dijaga agar tetap lestari, tetap bisa dimanfaatkan, membantu mendapatkan informasi terhadap orang tertentu dalam kaitannya dengan agama dan yang terkait di dalamnya?

Tulisan ini bertujuan memberikan gambaran tentang bagaimana keamanan dan perawatan arsip Gereja. Pembahasan ini mengkhususkan tentang keamanan dan perawatan arsip rahasia di Gereja. Gereja Katolik yang dipilih sebagai studi kasus penelitian ini adalah tiga paroki yakni paroki St. Antonius, Kotabaru, paroki St. Yohanes Rasul, Pringwulung, dan paroki Kristus Raja, Baciro. Ketiga Paroki ini terletak di Kota Yogyakarta. Latarbelakang pemilihan ketiga paroki ini karena ketiganya saling keterkaitan dalam sejarah. Salah satunya adalah sejarah bahwa Gereja Paroki St. Antonius, Kotabaru sebagai induk ini memekarkan menjadi Gereja Paroki Kristus Raja, Baciro (Kenangan, 2012: 
15). Selain sejarah, juga karena ketiga Gereja paroki ini menjadi tempat beribadah bagi para pendatang yang berasal dari luar daerah Kotabaru, Baciro, maupun Pringwulung. Melihat fenomena ini, tentulah akan terbayangkan bagaimana dan berapa banyak arsip gereja itu dikelola, dirawat, dan juga dijaga.

Berdasarkan penelusuran kami, khususnya di Indonesia kami belum menemukan penelitian yang berkaitan dengan perawatan dan keamanan arsip rahasia gereja. Oleh karena itu kami menilai bahwa studi kasus ini adalah penelitian pertama yang sebelumnya belum pernah dilakukan. Dalam hal ini juga kami menyatakan bahwa tulisan ini merupakan karya kami sendiri dan belum pernah diikutsertakan dalam segala bentuk publikasi manapun.

Persiapan menghadapi bencana itu perlu dilakukan, karena akan meminimalkan kerugian materi dan jiwa jika timbul. Lebih dari itu semua, baginya tujuan utamanya adalah untuk melindungi dan melestarikan khasanah kekayaan budaya bangsa (Mustafa, 2004). Meskipun demikian permasalahannya adalah tidak semua badan atau instansi sadar dan peduli terhadap pentingnya perlindungan terhadap arsip/khasanah yang dimilikinya.

Adapun contoh penelitian serupa dengan keamanan dan perawatan arsip. Pertama yaitu sebuah penelitian yang dilakukan oleh Erine Delviana. Penelitian tersebut berjudul "Perawatan dan Pemeliharaan Arsip Bagian Perawatan PT POS Indonesia (Persero) Palembang". Hasil temuannya adalah minimnya peralatan yang digunakan dalam penyimpanan arsip di ruang arsip bagian perawatan. Selanjutnya tidak adanya perawatan dan pemeliharaan arsip secara khusus untuk arsip yang disimpan dan tidak ada petugas khusus untuk merawat dan memelihara arsip. Kerusakan arsip pada ruangan arsip lebih banyak disebabkan oleh serangga, jamur, dan debu (Delviana, 2015) Penelitian kedua yaitu sebuah penelitian yang dilakukan oleh Cajetan Okechukwu Onyeneke. Ia menyelidiki bagaimana insiden bencana mempengaruhi Arsip Nasional di Nigeria
Tenggara. Hasil temuannya adalah didalam instansi tersebut terdapat prosedur pencegahan arsip terhadap bencana seperti; penilaian kesesuaian metode penyimpanan; penilaian lokasi koleksi dan display; aturan penggunaan peralatan; pemeriksaan rutin terhadap penggunaan peralatan; dan prosedur keamanan reguler. Meskipun demikian temuan selanjutnya mengungkapkan bahwa tidak ada latihan atau simulasi untuk staf arsip sehingga tidak adanya kesadaran staf dalam mempersiapkan diri ketika suatu bencana tiba (Onyeneke, 2017).

Kekhususan tulisan ini adalah yaitu meneliti tentang keamanan dan perawataan arsip gereja. Selain itu kami juga secara spesifik memilih arsip rahasia gereja yang ada di tiga tempat yakni paroki St. Antonius, Kotabaru, paroki St. Yohanes Rasul, Pringwulung, dan paroki Kristus Raja, Baciro. Dibawah ini akan dicantumkan beberapa tinjauan literatur pendukung untuk penelitian ini.

\section{Perawatan dan Keamanan Arsip}

Menurut Sulistyo B. (2003) ada beberapa metode pencegahan bencana. Pencegahan terhadap jamur dan lumut pada arsip dapat diantisipasi jika ruang penyimpanan memiliki kelembaban berada sekitar 50\% dengan suhu ruangan berkisah antara $18^{\circ}$ Celcius dan $24^{\circ}$ Celcius. Ventilasi menghambat pertumbuhan spora jamur. Oleh karena itu udara harus mengalir, bila mungkin menggunakan pendingin udara (air conditioner). Arsip harus dihindari dari panas (Ted Ling, 2008).

Pengamanan arsip mulai dari saat arsip diterima, diolah, digunakan oleh peneliti dan disimpan di rak. Evaluasi terhadap gedung arsip mencakup penilaian atas jendela, pintu dan langit-langit. Sistem pengamanan mampu menangkal orang yang tidak berwenang masuk dengan memanfaatkan alarm, jari-jari, panel pemantau, atau detektor gerakan yang disambungkan dengan alarm jarak jauh. Hanya arsiparis yang berwenang saja yang memiliki hak akses ke kawasan rak tempat arsip disimpan (Basuki, 2003). 


\section{Arsip dalam Gereja}

Dalam Kitab Hukum Kanonik (ed. Rubiyatmoko, 2006), kanon 486-491, menetapkan persyaratan agar setiap keuskupan mempunyai arsip tempat penyimpanan naskah-naskah atau surat resmi menyangkut urusan-urusan keuskupan baik yang bersifat rohani maupun duniawi. Kanon 486, paragraf (§) 1 menyatakan dengan tegas hal itu: "Semua dokumen yang menyangkut keuskupan atau paroki-paroki harus dijaga dengan seksama". Dengan kata lain, semua arsip keuskupan ataupun arsip perseorangan harus dijaga dan dipelihara secara baik.

Selain arsip keuskupan, kita harus mempunyai suatu arsip rahasia kuria tempat penyimpanan dokumen atau hal yang lebih sensitif misalnya perkara kriminal dibidang moral (Kan. 489-490). Salah satu buku yang dapat menjadi pegangan khususnya di kuria keuskupan maupun tarekat adalah buku "Mengurus Arsip Gereja”(Go, 2006). Salah satu pembahasan di dalamnya adalah bagaimana aturan penyimpanan dan penataan serta pemeriharaan dan perawatan arsip gereja.

\section{Prosedur Pengarsipan Gereja}

Hal-hal yang menyangkut prosedur (tata cara) pidana harus disimpan dalam arsip rahasia. Jika suatu tuduhan kejahatan sudah diketahui Ordinaris, dia wajib melakukan penyelidikan atau investigasi awal baik secara pribadi maupun lewat orang lain (Kan. 1717, §1). Kanon 1719 berbicara soal akta penyelidikan dan dekrit-dekrit ordinaris yang harus disimpan dalam arsip rahasia kuria. Kanon ini mengandaikan salinan dokumen penyelidikan yang telah dilakukan dan kemudian dipelihara secara baik. Misalnya: dokumen tentang penyelidikan terhadap klerus yang dituduh melakukan pemerkosaan terhadap anakanak atau orang dewasa, terhadap siapa saja yang termasuk dalam kategori ini (sexual abuse dan sexual misconduct: Pedophilia dan Ephebophilia).
Dokumen yang termasuk dalam arsiparsip umum tidak boleh dipindahkan kecuali dengan persetujuan Uskup atau moderator kuria bersama dengan kanselir. Mereka hanya bisa dipindahkan untuk jangka waktu yang singkat (bdk. Kan. 488). Dalam keadaan takhta lowong arsip atau almari rahasia dilarang untuk dibuka oleh Administrator diosesan, kecuali dalam kasus yang sungguh darurat (Kan. 490, §2).

\section{Arsip Rahasia dan Arsip Biasa Gereja}

Kitab Hukum Kanonik membedakan arsip yang disimpan di sekretariat keuskupan atau tarekat ke dalam dua jenis yakni: arsip rahasia dan arsip biasa (Kusmawanta, 2009). Kodeks menjelaskan pentingnya menyimpan arsip rahasia dalam kanon 489-490. Sedangkan arsip biasa kodeks tidak menyebutkan secara spesifik, begitu pula untuk arsip perseorangan. Kodeks hanya memberikan keterangan bahwa Uskup diosesan diberi kewenangan untuk mengupayakan pengadaan arsip lain (Kan. 491, §1-2).

Kodeks 1983 secara rinci menyebutkan dokumen-dokumen yang harus disimpan dalam arsip atau almari rahasia itu, antara lain:

1. Dispensasi dalam tata batin (forum internum) yang bukan sakramen dari halangan nikah tersembunyi (Kan. 1082),

2. Perkawinan yang dilangsungkan secara rahasia (Kan. 1133),

3. Dispensasi dari halangan tahbisan (Kan. 1047-1048),

4. Dekrit pengeluaran (dismissal) seseorang anggota dari Tarekat (Kan. 700),

5. Dokumen-dokumen yang berkaitan dengan kehilangan status klerikal melalui hukuman pemecatan, keputusan pengadilan atau dekrit administratif yang menyatakan ketakabsahan tahbisan dan 
dispensasi yang diperoleh melalui reksrip Takhta Apostolik ( Kan. 290293),

6. Dokumen-dokumen atau salinan dokumen perkara-perkara kejahatan di bidang moral (Kan 489, § 2).

Selain almari arsip rahasia, pada setiap keuskupan atau tarekat hendaknya memiliki arsip perseorangan yang memuat pelbagai macam informasi biografik dan akademik, dokumen penempatan, suratsurat yang dikirim menyangkut klerus, catatan medis dan psikiatri. Seperti yang sudah dijelaskan di atas Uskup diosesan memiliki kewenangan untuk mengadakan arsip lain seperti penyimpan dokumendokumen dari Gereja Katedral, Paroki dan Gereja - Gereja lain. Uskup diosesan dapat juga membuat arsip sejarah yang menyimpan dokumen yang memiliki nilai historis.

\section{METODE}

Penelitian ini adalah penelitian deskriptif dengan menggunakan metode pendekatan kualitatif. Nasution (1988) mengemukakan penelitian kualitatif pada hakekatnya ialah mengamati orang dalam lingkungan hidupnya, berinteraksi dengan mereka, berusaha mengamati bahasa dan tafsiran mereka tentang dunia sekitarnya. Melalui metode pendekatan kualitatif didapatkan mendalam tentang sikap dan perasaan yang dialami informan sehingga informasi yang didapatkan lebih luas dan memiliki kredibilitas yang tinggi. Sampel pada penelitian ini berjumlah 3 Paroki Gereja di Yogyakarta yang terdiri atas; St. Antonius Kotabaru, St. Yohanes Rasul Pringwulung, dan Kristus Raja, Baciro.

Pemilihan ketiga paroki ini karena ketiganya saling keterkaitan dalam sejarah. Salah satunya adalah sejarah bahwa Paroki St. Antonius, Kotabaru sebagai induk ini memekarkan menjadi Paroki Kristus Raja, Baciro (Kenangan, 2012: 15). Selain sejarah, juga karena ketiga paroki ini menjadi tempat beribadah bagi para pendatang yang berasal dari luar daerah Kotabaru, Baciro, maupun Pringwulung
Teknik pengumpulan data yang digunakan dalam penelitian ini yaitu menggunakan wawancara mendalam dengan staff dan Pastor. Teknik pengumpulan data secara wawancara tujuannya yaitu untuk menggali informasi dari informan secara lebih dalam. Stainback dalam Sugiyono (2014) mengemukakan bahwa dengan wawancara maka peneliti akan mengetahui hal-hal yang lebih mendalam tentang partisipan dalam menginterpretasikan situasi dan fenomena yang terjadi, dimana hal ini tidak bisa ditemukan melalui observasi.

\section{PEMBAHASAN}

Bagi Gereja, arsip adalah aset yang sangat penting dan berharga dalam rangka menunjang pelayanan administrasi dan membantu mewujudkan misi Gereja. Setiap Gereja berkewajiban untuk mengelola dan menjaga arsip Gereja sebaik-baiknya. Hasil penelitian kami menemukan bahwa ketiga gereja yang menjadi objek penelitian ini sama-sama bernaung di bawah Keuskupan Agung Semarang, namun ketiga Gereja ini mempunyai kebijakan masing-masing dalam mengelola arsip Gereja.

Menurut Azmi (2016) ditinjau dari nilai guna arsip, arsip statis adalah arsip yang sudah tidak dipergunakan lagi secara langsung untuk kegiatan operasional manajemen organisasi pencipta arsip (creating agency), tetapi memiliki nilai guna permanen. Berdasarkan teori ini, arsip rahasia gereja dapat dikategorikan sebagai arsip statis karena meskipun tidak digunakan lagi untuk kepentingan operasional, namun arsip rahasia gereja diakui keberadaannya. Pada hasil dan pembahasan ini dibagi menjadi 4 bagian diantaranya; ruang penyimpanan arsip gereja, tempat penyimpanan arsip rahasia gereja, perawatan arsip rahasia gereja, dan upaya pencegahan arsip rahasia terhadap bencana.

\section{a. Ruang Penyimpanan Arsip Gereja}

Pemilihan ruangan untuk arsip hendaknya memperhatikan kelayakan ruangan misalnya jauh dari aktivitas kerja. Pemilihan ruang arsip jauh dari aktivitas kerja dapat memberikan dampak positif bagi arsip misalnya; terhindar 
dari tinta, lem, dan peralatan kerja lainnya yang staff yang dapat mengakibatkan arsip kertas menjadi cepat rusak. Hasil penelitian di lapangan, Gereja St. Yohanes Rasul Pringwulung menyimpan arsip berbentuk kertas pada satu ruangan yang tergabung dengan ruang kerja bendahara paroki dan ruang kerja sekretariat paroki. Gereja ini tidak memiliki ruang atau gedung khusus untuk penyimpanan arsip. Gereja St. Yohanes Rasul Pringwulung ini tergolong baru sehingga arsip yang dimiliki masih relatif sedikit. Penggabungan ruang arsip, ruang kerja bendahara, dan ruang kerja sekretariat dikarenakan sangat terbatasnya ruang yang dimiliki oleh paroki ini.

Kondisi ini sedikit berbeda dengan Gereja St Antonius Kotabaru dan Gereja Kristus Raja Baciro. Di Gereja St. Antonius Kotabaru, arsip berbentuk kertas juga disimpan tergabung dengan ruang kerja. Namun bedanya di paroki ini penempatan arsip dibagi menjadi 3 ruangan yaitu; ruang kerja dan arsip dewan paroki; ruang kerja dan arsip sekretariat paroki, dan ruang khusus arsip lama. Selanjutnya pada Kristus Raja Baciro, arsip berbentuk kertas disimpan juga pada 3 ruangan terpisah yaitu; ruang kerja dan arsip sekretariat paroki, ruang kerja dan arsip dewan paroki, dan ruang arsip rahasia. Ruang penyimpanan arsip dokumen kertas ketiga gereja ini berbeda-beda. Ketiga gereja ini belum mempunyai ruang yang digunakan untuk arsip sehingga penyimpanan arsip masih tergabung dengan ruang kerja. Kesamaan permasalahan mendasar yang dialami ketiga gereja ini yaitu adalah keterbatasan ruang dan infrastruktur yang dimiliki oleh Gereja.

\section{b. Penyimpanan dan Hak Akses Arsip Rahasia Gereja}

Tempat penyimpanan arsip rahasia di Gereja St. Yohanes Rasul Pringwulung adalah almari. Dalam hal ini arsip rahasia masih menjadi satu dengan arsip biasa. Tidak ada pembedaan atau perlakuan khusus terhadap arsip rahasia. Almari yang digunakan untuk menyimpan arsip ini terbuat dari kayu. Bentuk almari kayu ini permanen karena pada sisi belakang dan samping dihubungkan langsung dengan dinding. Sisi muka almari adalah kaca, dan dilengkapi dengan kunci almari. Pada Gereja Paroki ini, orang yang berhak mengakses arsip rahasia adalah pastor dan staf. Artinya pastor dan staf mempunyai hak akses yang sama terhadap arsip rahasia tersebut.

Pada Gereja St. Antonius Kotabaru tempat penyimpanan arsip rahasia masih digabungkan dengan arsip biasa sehingga tidak ada pembedaan antara kedua kategori arsip tersebut. Namun bedanya, apabila arsip Gereja St Yohanes Rasul Pringwulung disimpan pada almari kayu, pada Gereja St. Antonius Kotabaru ini arsip disimpan pada almari besi. Selanjutnya Pada Gereja St. Antonius Kotabaru ini, orang yang mempunyai hak akses pada arsip rahasia adalah pastor dan staf. Kondisi ini sama dengan Gereja St. Yohanes Rasul Pringwulung di mana Pastor dan staf mempunyai hak akses yang sama terhadap arsip rahasia.

Selanjutnya, di Gereja Kristus Raja Baciro tempat penyimpanan arsip rahasia sudah dipisahkan dari arsip biasa. Tempat penyimpanan arsip rahasia yaitu almari kayu dan dilengkapi dengan kunci almari. Almari arsip rahasia ini ditempatkan pada ruang kerja pastor. Dalam hal ini pastor adalah orang yang memegang penuh akses terhadap arsip rahasia sehingga kunci almari hanya pastor yang memegangnya.

\section{c. Pemeliharaan Arsip Rahasia}

Gereja St. Yohanes Rasul Pringwulung, Gereja St. Antonius Kotabaru, dan Gereja Kristus Raja Baciro mempunyai cara yang sama dalam upaya menjaga dan memelihara arsip rahasia ini. Sebagai contoh agar terhindar dari cairan, setiap arsip rahasia yang berbentuk kertas dilapisi menggunakan plastik. Selain itu sebagai upaya pemeliharaan, hal yang dilakukan yaitu pembersihan dari debu dan kotoran. Meskipun demikian kegiatan pembersihan ini tidak dilakukan secara rutin. Temperatur atau suhu pada ruangan arsip rahasia ini belum menjadi perhatian. Salah satu faktor yang menyebabkan hal ini terjadi adalah 
kurangnya pemahaman dan pengetahuan tentang perawatan arsip.

\section{d. Upaya Pencegahan Kerusakan Arsip Rahasia Terhadap Bencana}

Gereja St. Yohanes Rasul Pringwulung belum menyiapkan upaya preventif terkait dengan perlindungan arsip rahasia berbentuk dokumen kertas dari bencana alam seperti gempa bumi, gunung meletus, atau bencana akibat manusia seperti kebakaran, bom, dsb. Hal semacam ini sebenarnya sudah menjadi kekhawatiran dari pihak Gereja namun hingga saat ini belum ada rencana atau tindak lanjut untuk perlindungan arsip tersebut. Pada Gereja ini, almari yang dipakai adalah almari yang terbuat dari kayu. Dalam hal ini almari kayu belum memenuhi standar sebagai tempat penyimpanan arsip. Selain almari kayu bisa lapuk dan mengakibatkan kerusakan arsip didalamnya, almari kayu juga rentan terhadap kebakaran dan tidak tahan apabila tertimpa reruntuhan akibat bencana alam.

Kondisi ini sama dengan Gereja Kristus Raja Baciro, di mana Gereja ini juga menyimpan arsip rahasia pada almari kayu yang rentan terhadap bencana. Meskipun pernah mengalami kerusakan, Gereja Kristus Raja Baciro belum menyiapkan upaya preventif terkait dengan perlindungan arsip rahasia ini. Selanjutnya, Gereja St.Antonius Kotabaru juga tidak menyiapkan upaya preventif terhadap arsip berbentuk dokumen kertas. Pada Gereja ini almari yang digunakan untuk tempat penyimpanan arsip rahasia adalah almari besi. Pada kondisi tertentu almari besi tahan terhadap bahaya kebakaran dan reruntuhan akibat gempa atau gunung meletus. Namun pada kondisi bencana alam yang besar, almari ini belum cukup sebagai tempat penyimpanan arsip yang aman bencana.

\section{SIMPULAN}

Dalam Kan. 486,§1 menyatakan dengan tegas bahwa: "Semua dokumen yang menyangkut keuskupan atau paroki-paroki harus dijaga dengan seksama". Hasil penelitian penulis dengan sampel 3 paroki yakni St. Antonius Kotabaru, St. Yohanes Rasul Pringwulung dan Kristus Raja Baciro, hukum yang ada di kanon tersebut belum sepenuhnya ditaati. Kesimpulan penulis ini diperoleh dari data-data tentang bagaimana ketiga paroki ini memperlakukan dokumen-dokumen tersebut. Ketiganya dalam hal perawatan terhadap arsip baru pada penyusunan yang rapi dan baik, penomoran (katalog), dan pencegahan kerusakan dengan memasukkan arsip tersebut di dalam plastik. Namun perawatan secara berkala, standarisasi ruangan penyimpanan seperti adanya ruangan yang mampu menjaga arsip terhindar dari bencana alam maupun bencana lainnya, belum diupayakan. Ketiga paroki ini rupanya sedang berbenah, dan mulai mengarah untuk perawatan dan keamanan yang lebih baik lagi.

\section{DAFTAR PUSTAKA}

Akuffo, M. N., \& Adams, M. (2016). Records management practices in ecumenical tertiary institutions: The trinity theological seminary in focus. Archives and Manuscripts, 44(2), 61-72. https://doi.org/10.1080/01576895.2016 .1191035

Basuki, S. (2003). Manajemen Arsip Dinamis. Jakarta: PT. Gramedia Pustaka Utama.

Delviana, E. (2015). Perawatan dan Pemeliharaan Arsip di Ruang Arsip Bagian Perawatan PT Pos Indonesia (Persero) Palembang. Retrieved from http://eprints.polsri.ac.id/2451/6/BAB V.pdf

Go, P. (Ed.). (2006). Mengurus arsip Gereja (I). Jakarta: Konfrensi Waligereja Indonesia.

Kenangan, T. B. (2012). Gereja Kristus Raja Baciro Yogyakarta. Yogyakarta: Cahaya Timur Offset.

Kusmawanta, D. G. (2009). Imam di ambang batas. Yogyakarta: Kanisius.

Mustafa, B. (2004). Lindungi Aset Perpustakaan Anda dari Bencana dengan Menyiapkan "Disaster Preparedness Plan." IPB Bogor, 1-15. Retrieved from http://dev.perpusnas.go.id/assets/uploa 
ds/2016/02/5_artikel_mustafa_lindungi_ aset_perpustakaan.pdf

Onyeneke, C. O. (2017). Impact of disaster on access to records of National Archives of South East, Nigeria. Collection Building, 36(2), 63-68. https://doi.org/10.1108/CB-12-20160033
Rubiyatmoko, R. (Ed.). (2006). Kitab Hukum Kanonik (Codex Iuris Canonici) (Pertama). Jakarta: Konfrensi Waligereja Indonesia.

Ted Ling. (2008). Keeping Archives. (B. Jackie, E. Kim, L. Rowena, \& C. Smith, Eds.) (Third). Australia: Australian Society of Archivists Inc. 